\title{
The moderating effects of national culture on the development of organisational learning culture: $A$ multilevel study across seven countries
}

\author{
Miha Škerlavaj, Chunke Su, Meikuan Huang ${ }^{* *}$
}

This study examines the moderating effects of national culture dimensions (Hofstede 1980) on three key elements in the development of organisational learning culture: information acquisition, information interpretation and behavioral and cognitive changes. Data were collected from 1333 companies in three CEE countries (Slovenia, Croatia, Macedonia) and other regions. The results showed that four national cultural dimensions (power distance, individualism, masculinity, and uncertainty avoidance) had no significant moderating effects on the relationship between information acquisition and information interpretation. However, the relationship between information interpretation and behavioral and cognitive changes was positively moderated by power distance, and negatively moderated by individualism, masculinity and uncertainty avoidance.

Diese Studie untersucht die moderierende Wirkung der nationalen KulturDimensionen (Hofstede 1980) auf drei wesentliche Elemente in der Entwicklung von organisationaler Lernkultur: Informationsbeschaffung, Informationsinterpretation und sowie kognitiver und Verhaltens-Veränderungen. Die Daten wurden von 1333 Unternehmen in drei MOE-Ländern (Slowenien, Kroatien, Mazedonien) und anderen Regionen erhoben. Die Ergebnisse zeigten, dass vier nationale kulturelle Dimensionen (Machtdistanz, Individualismus, Männlichkeit und Unsicherheitsvermeidung) keine signifikanten Auswirkungen auf die Beziehung zwischen Informationsbeschaffung und Informationsnterpretation hatten. Allerdings wurde die Beziehung zwischen Informationinterpretation und kognitiven und Verhaltens-Veränderungen positiv durch Machtdistanz und negativ durch Individualismus, Maskulinität und Unsicherheitsvermeidung moderiert.

Keywords: organisational learning; national culture; information acquisition; information interpretation; behavioral and cognitive changes.

\footnotetext{
Manuscript received: 03.03.2012, accepted: 27.08.2012 (1 revision)

** Miha Škerlavaj, University of Ljubljana, Slovenia \& BI Norwegian Business School, Oslo, Norway. Main research interests: Organisational networks, innovation, knowledge, learning, organisational culture. Corresponding address: miha.skerlavaj@ef.uni-lj.si

Chunke Su, University of Texas at Arlington, USA. Main research interests: Knowledge management, information sharing and transfer, communication technology.

Meikuan Huang, California State University, Stanislaus, USA. Main research interests: Group communication, knowledge management, learning, communication and knowledge networks.
} 


\section{Introduction}

Organisational learning was found to be a critical source of sustainable competitive advantage (de Geus 1988), a driving force for corporate performance (Sorenson 2003; Stata 1989; Tucker/Nembhard/Edmondson 2007), a catalyst for innovation (Bates/Khasawneh 2005), and an influential factor on organisational outcomes such as job satisfaction and turnover intention (Egan/Yang/Barlett 2004). Meanwhile, increasing globalization in the past few decades has driven more organisations to operate across national boundaries and establish a culturally diversified workforce (Kirkman/Shapiro 1997), While the literature on organisational learning is vast and growing (Arthur/Huntley 2005; Easterby-Smith/Lyles 2004; Schwab/Miner 2008; Zellmer-Bruhn/Gibson 2006), little is known about how organisational members' learning process is influenced by their national cultural backgrounds. While research on a related concept of cross-border knowledge transfer in MNC is vast (e.g. Chen/Sun/McQueen 2010; Gupta/Govindarajan 2000; Hocking/Brown/Harzing 2007), this is less so for organisational learning across various national cultures (Michailova/Hutchings 2006; Tsang 1999, 2002; Walczak 2008).

In this paper we focus on organisational learning culture. Škerlavaj (2007) defined organisational learning culture as a set of norms and values about the functioning of an organisation that put high emphasis and value on elements of organisational learning process (information acquisition, information interpretation, and behavioral and cognitive changes). It is a combination of different culture types within the competing values framework (Denison/Spreitzer 1991). While there has been few studies studying organisational learning culture related to organisational performance and to innovations in different countires, the actual mechanisms of how specific dimensions of a national culture could affect organisational learning culture have yet to be discovered (Dimovski/Škerlavaj/Kimman/Hernaus 2008; Hong/Easterby-Smith/Snell 2006).

Broadly speaking, organisational learning is a multilevel process (Holmquist 2004; Ibarra/Kilduff/Tsai 2005; Sanchez 2001). Scholars have advocated for the importance of using a multilevel approach to examine organisational culture and climate (Yammarino/Dansereau 2010), as well as organisational learning across the individual, group and organisational level (Crossan/Lane/White 1999). Individual members not only work within a specific group and organisational context, but also within a specific national culture at large ((Hofstede 1983)). Therefore it is crucial to use a multilevel approach to uncover the potential cross-level interaction between national cultural characteristics and organisational learning culture as well.

The goal of this study is to develop a multilevel model to explain how national culture could influence the development of organisational learning culture. The 
focus of this study is to examine how the interrelationships among these three learning elements could be moderated by different dimensions of a national culture (Hofstede 1980, 2001; Hofstede/Hofstede 2005). This approach is theoretically important because it provides an extended and comprehensive perspective in conceptualizing organisational learning above and beyond the traditional organisational boundary.

More importantly, this study seeks to empirically test the multilevel models by analyzing data collected from organizations in Central and East European countries (Slovenia, Croatia, and Macedonia) and other regions (Turkey, Spain, Malaysia, and South Korea). Existing research has highlighted the importance of examining national contextual factors (such as national institutional development) on organizational development in CEE countries (Soulsby/Clark 2011). Other research has studied the relationship between organizational culture and knowledge management in a particular industry of a particular CEE country (Omerzel/Biloslavo/Trnavcevic 2011). However, to date, there exists scant research that focuses on the co-evolution of national culture and organisational learning culture across different industries and CEE countries. Thus, in the context of increasing globalization and transformation of national and organizational cultures in CEE countries (Clark/Soulsby 2009), there is a pressing need to study management issues not only within, but also across the organizational, industrial, and national levels. Therefore, this study contributes to CEE management scholarship by unraveling the effects of national cultural characteristics on organisational learning across a diverse array of industries in both CEE and non-CEE countries.

This paper is organized as follows. First, we begin by presenting the concept of organisational learning culture and dimensions of national culture. Next, we develop two sets of hypotheses about the moderating effects of national culture on the development of organisational learning culture. Specifically, the first set of hypotheses concerns the relationship between information acquisition and information interpretation, as well as the moderating roles of national cultural dimensions on this relationship. The second set of hypotheses investigates the influence of information interpretation on behavioral and cognitive changes, and how national cultural dimensions could moderate such relationship. Then we use hierarchical linear modeling (HLM) analysis to test the multilevel models with survey data from seven countries across Europe and Asia. Finally, we discuss the findings and their implications, as well as the limitations and future directions of this study. 


\section{Theories and hypotheses}

\section{Organisational learning culture}

There is a wealth of literature dedicated to defining and conceptualizing organisational learning. It is a "process of improving actions through better knowledge and understanding" (Fiol/Lyles 1985: 803), and "a continuous testing of experience and its transformation into knowledge available to whole organisation and relevant to their mission" (Senge 1990, p. 6). Tsang (1997) contrasts organisational learning with learning organisation in terms of its descriptive and theoretical nature vis-à-vis normative and practical nature of learning organisation. Huber (1991) conceives organisational learning as an integrated process of information acquisition, information distribution, information interpretation and organisational memory. Argyris and Schön (1996) state that organisational learning emerges when organisations acquire information (understandings, know-how, techniques and procedures) of any kind by any means. What these perspectives share in common is that organisational learning is a sequential and dynamic process in which organisational members acquire new information, develop new knowledge, and modify their behaviors accordingly (Huber 1991; Levitt/March 1988; Murray/Donegan 2003; Slater/Narver 1995).

A crucial aspect of organisational learning is the development of organisational learning culture, which is defined as a set of organisational norms and values that support systematic and in-depth approaches to achieve higher-level organisational learning (Škerlavaj et al. 2007). Centering around the functioning of an organisation (Schein 1992), these organisational norms and values aim to support various forms of higher-level organisational learning, such as doubleloop (Argyris/Schön 1996), strategic (Bhattacharya 1985), or generative learning (Wittrock 1974, 1992). The conceptualization of organisational learning culture is proposed based on the integration of key organisational learning processes (Huber 1991) and competing values frameworks of organisational culture and development (Denison/Spreitzer 1991).

The development of organisational learning culture is achieved through consecutive phases of (1) information acquisition, (2) information interpretation, and (3) behavioral and cognitive changes (Garvin 1993; Huber 1991). Organisations ascribing high importance to organisational learning culture must first acquire information, and then interpret it to fully understand its meaning and implications. Based on the interpretation and sense-making of acquired information, organisational members would make behavioral and cognitive changes accordingly (Garvin 1993; Huber 1991). These three sequential phases are required to complete the transition from "knowledge in words" to "knowledge in action" in organisational learning (Škerlavaj et al. 2007). Therefore, organisations that have developed a strong learning culture are 
effective in acquiring and transferring knowledge. Employees working in a strong learning culture are also likely to modify behaviors and perceptions as a result of learning and interpreting newly acquired information. When a learning culture is developed in an organisation, an integrated sequential process of information acquisition, interpretation and behavioral changes is written in the organisation's "DNA" and becomes an integral part of the organisational culture. Within such learning culture, aspirations to learn new information, interpretation of existing information, and action based on acquired information are well rooted among organisational members. This is the reason why this study focuses on how national culture could influence the development of organisational learning culture, rather than organisational learning processes in general.

Previous research has suggested and supported the connections among the above three key elements in the development of organisational learning culture. Several single-country studies (Hernaus/Škerlavaj/Dimovski 2008; Mok Kim Man/Dimovski/Škerlavaj 2007; Škerlavaj et al. 2007; Zagoršek/Dimovski/Škerlavaj 2009) and a two-country (Škerlavaj/Dimovski 2009) research have provided empirical support to a strong positive effect of information acquisition on information interpretation, and an even stronger positive effect of information interpretation on behavioral and cognitive changes. However, none of these studies found a direct relationship between information acquisition and behavioral and cognitive changes. Such finding suggests that information interpretation is a vital phase that mediates information acquisition and cognitive and behavioral changes. After the employees in the organisations acquire information in the initial phase, they must interpret and make sense of such information before they make any behavioral or cognitive changes. As an extension to aforementioned studies, this study proposes to test these two fundamental relationships again with larger and more diversified samples (organisations from seven countries), so as to further assess the external generalizability of these three core elements in the development of organisational learning culture. Further, these two hypotheses, which are proposed at the organisational level, will be incorporated as the ground-level processes into the development of multilevel model in the following sections.

Hypothesis 1a: Organisations' emphasis on the importance of information acquisition is positively related to their emphasis on the importance of information interpretation.

Hypothesis 1b: Organisations' emphasis on the importance of information interpretation is positively related to their behavioral and cognitive changes. 


\section{Dimensions of national culture}

Organisations are nested within nations, and tend to develop and evolve in ways that are compatible with the surrounding national culture (Sagiv/Schwartz/Arieli 2010). To function effectively, organisations must gain and maintain some public legitimacy (Kostova/Roth 2002), and adapt to the cultural characteristics in the home or host nation. The same principle is true for the development of organisational learning culture, which is driven and constrained by not only the demographics of employees (Wang/Yang/McLean 2007), but also its organisational, social, and national contexts (Škerlavaj et al. 2007). Thus it is imperative to contextualize organisational learning by investigating how specific national cultural characteristics could influence organisational learning processes (Meyer 2007). To address this research question, this study focuses on four key dimensions of Hofstede's national culture models (1980; 1984, 1991; 2001): individualism-collectivism, power distance, uncertainty avoidance, and masculinity-femininity. Notwithstanding being subject to various criticism (Holden 2002; Wilkesmann et al. 2009; Williamson 2002), Hofstede's models have been widely accepted and credited as a leading theoretical framework to study national cultures and cross-cultural differences (Chandy/Williams 1994; Kogut/Singh 1988; Michailova/Hutchings 2006). In addition, the validity of Hofstede's national cultural dimensions has been tested in various settings over time (Mouritzen/Svara 2002; Shane/Venkatraman 1996).

Despite the popularity in using Hofstede's models to understand the similarity and variance in national cultures, few studies have applied his models to examine the effects of national cultural dimensions on organisational learning. To bridge this research gap, this study seeks to explore the moderating effects of each of the four key national cultural dimensions on the development of organisational learning culture, specifically on the sequential relationships among information acquisition, information interpretation, and behavioral and cognitive changes. Our model does not include the fifth national cultural dimension of Hofstede's models, long-term orientation, because it was not included in the original 4 primary cultural dimensions by Hofstede. Moreover, the data in this dimension was not available for the countries we investigated in this study.

\section{Power distance}

Power distance is defined as the extent to which a society accepts the fact that power in its institutions and organisations is distributed unequally (Hofstede 2001). The characteristics of a national culture with high power distance include low accessibility of supervisors to their subordinates, less trust, and more stringent hierarchical structure within organisations. Organisational members influenced by high power distance national culture are more likely to accept hierarchical differences and abide by the authoritarian leadership, because they 
believe that the supervisors are more knowledgeable and should have decisionmaking power (Sagie/Mainiero/Koslowsky 2000). In contrast, the low power distance national culture is characterized by a decentralized distribution of decision-making power, support for individual thinking, and smooth supervisorsubordinate communication and cooperation (Hofstede 1991). Therefore, national cultures with different levels of power distance could exert distinct influence on how organisational members acquire and interpret information, as well as how they modify their behaviors after learning.

Previous research has applied the power distance cultural dimension to studying how students seek feedback in the class learning environment (Hwang/Francesco 2010). The authors argue that students with high power distance would feel more comfortable learning from their fellow students rather than from the superiors - professors. Other studies have extended the research on power distance from individual to the organisational learning settings. Couto and Vieira (2004) found that high power distance was negatively related to research and development activities in organisations, and that the low power distance would facilitate intra-organisational cooperation and problem solving. These finding are consistent with Nakata and Sivakumar's work (1996), which showed that the low power distance culture would promote cooperation and exert positive influence on $R \& D$ research and innovation within organisations. In their qualitative comparative study of German and Hong Kong organisations, Wilkesmann, et al. (2009) claim that a high power distance culture would negatively affect knowledge transfer because it helps preserve a strict and omnipresent hierarchical organisational structure which would hinder vertical knowledge sharing within organisations. Taken together, previous studies have provided empirical support to Hofstede's (1991) assertion that a high power distance national culture would impede innovation of organisations nested in such culture.

Applying the power distance cultural dimension to the development of organisational learning culture, we speculate that organisations in a high power distance culture would have greater difficulties in the development of an effective organisational learning culture. First, since individual employees in a high power distance culture tend to give up the decision-making power to their supervisors and refrain from active learning, they are less likely to make dedicated efforts on interpreting the information they have acquired. Organisational members are more hesitant to take ownership of the information they have, as well as to make sense of the information they have obtained. Second, employees in a high power distance culture are less likely to modify their behaviors or change their perceptions as a result of information interpretation, because they believe their behaviors and cognition should conform to superior expectations and managerial control. Therefore, given the voluntary nature of knowledge transfer and organisational learning 
(Osterloh/Frey 2000), organisational members in a high power distance culture are less motivated to engage in quality information interpretation and deliberate behavioral and cognitive modifications. Consequently, it is more challenging to develop an effective organisational learning culture in a high power distance cultural context. Hence, we propose the following hypotheses:

Hypothesis 2a: The impact of information acquisition on information interpretation within organisations is weaker in national cultures with high power distance than with low power distance.

Hypothesis $2 b$ : The impact of information interpretation on behavioral and cognitive changes within organisations is weaker in national cultures with high power distance than with low power distance.

\section{Individualism-collectivism}

Central to Hofstede's national culture models is the development of the individualism-collectivism construct (Michailova/Hutchings 2006: 389). Hofstede's proposition of this national cultural dimension is based on previous work in organisational theory on self- and collectivity-orientation (Parsons/Shils 1951), as well as cooperation and competition in the human society (Mead 1967). The individualism-collectivism construct consists of two opposite cultural dimensions that focus on the relative importance of individual versus group interests (Hwang/Francesco 2010). The contrast between individualism and collectivism has been extensively studied to explain a variety of organisational phenomena (Adler 2002), such as creativity and innovation (Eisenberg 1999), student learning (Hwang/Francesco 2010; Wagner 1995) and technology mediated learning (Arbaugh/Benbunan-Fich 2006; Hornik/Tupchiy 2006). This paper takes a further step to examine the moderating effects of individualism-collectivism on the development of organisational learning culture.

According to Hofstede, an individualistic culture is characterized by loose ties between individual members (Hofstede 1980), individuals being the smallest unit of the society, and the superiority of independence and personal achievement to collective interests (Hofstede 2001). In an individualist culture, people emphasize on task achievement and the realization of personal values, even at the expense of interpersonal relationships (Kim/Triandis/Kagitcibasi/ Choi/Yoon 1994). On the contrary, a collectivist national culture is composed of strong and cohesive groups of people (Hofstede 1980). In such cultural context, the smallest unit of the society is the family, and collective interests take precedence over individual benefits and values (Hofstede 2001). In addition, a collectivist culture accentuates interdependence and building a harmonious relationship between individuals, sometimes even at the expense of task achievement (Kim et al. 1994). 
The individualism-collectivism cultural dimension has been found to influence various organisational processes and outcomes. A recent meta analysis of field studies (Bell 2007) shows that collectivism has emerged to be one of the strongest predictors of team performance. For example, organisational members tend to behave more cooperatively when their business unit emphasizes on collectivistic rather than individualistic cultural values (Chatman/Spataro 2005). Further, Ilies, Wagner, and Morgeson (2007) found that affective linkages between group members were higher where groups had collectivistic tendencies. Scholars have also explained the influence of collectivism on group and organisational behaviors through five facets of psychological development: preference for in-groups, reliance on in-groups, concern for in-groups, acceptance of in-group norms, and prioritization of in-group goals (JacksonColquitt/Wesson/Zapata-Phelan 2006). Therefore, groups and organisations within a collectivistic cultural context tend to demonstrate a greater level of interpersonal reliance and acceptance for collective actions.

More specifically, individualism-collectivism is viewed as the major distinctive influence on how various groups of people process and deal with information (Bhagat/Kedia/Harveston/Triandis 2002; Earley/Gibson 1998; Hofstede 1980; Hofstede 1991; Triandis 1995, 1998). Bhagat et al. (2002) claim that people in individualistic societies perceive information to be independent of its context, while collectivistic cultures stress the context in which information is conceived, interpreted and shared. When studying cultural influences on knowledge sharing in China and Russia, Michailova and Hutchings (2006) propose that collectivism leads to solidarity and frequent information exchanges among organisational members, which in turn would lead to intensive knowledge sharing (especially within groups). Therefore, the supremacy and frequency of interpersonal interactions in a collectivist culture not only facilitate information sharing among organisational members, but also motivate them to interpret the information based on specific organisational contexts and social cues. In contrast, organisational members in an individualistic culture are less likely to engage in collective information exchange, clarify with other members to reach a shared understanding of information, or interpret acquired information based on its organisational, social and cultural contexts. Hence, we expect that organisations situated in nations with a stronger individualistic national culture will exhibit a weaker positive relationship from information acquisition to information interpretation in the development of organisational learning culture. We propose the following hypothesis:

Hypothesis 3a: The impact of information acquisition on information interpretation within organisations is weaker in individualistic than in collectivist national cultures.

The differences between individualistic and collectivist national cultures also influence the process of converting interpreted information into actionable 
knowledge (i.e. to implement behavioral and cognitive changes based on the interpretation of acquired information). Organisational members in a collectivist culture are more sensitive to the context in which information is processed (Nisbett 2003), and tend to pay more attention to the tacit dimension of organisational knowledge (Bhagat et al. 2002). Previous research has suggested that intensive interpersonal relationships facilitate the transfer of tacit knowledge in organisations (Nonaka/Takeuchi 1995). Thus we speculate that a collectivistic culture would support and enhance individuals' tendency to make behavioral and cognitive changes based on their interpretations of information acquired from the organisational context. Further, Brickson (2007) found that the individualistic-collectivist orientation engendered distinct patterns of relations amongst internal stakeholders and provided unique potential to advance certain forms of social value. As such, the relationships formed among employees in a more collectivistic organisation are more likely to be based on preference and concerns for in-group actions, thereby increasing the likelihood of employees' behavioral and cognitive changes based on social influences and collective values. In contrast, organisational members in an individualistic culture tend to pay less attention to the shared context of information interpretation, and are less motivated and capable of converting knowledge (especially tacit knowledge) into behavioral and cognitive changes. Even if they do modify their cognitive and behavioral tendencies, such changes tend to be driven by their individual preferences and personal values, rather than by the meaning they derive from the information interpretation process. Therefore, when organisations place strong emphasis on information interpretation, such value is more likely to be observed, shared, and practiced by members in collectivist rather than individualist cultures. Thus we expect that organisations nested within a stronger individualistic national culture will demonstrate a weaker positive relationship from information interpretation to behavioral and cognitive changes.

Hypothesis 3b: The impact of information interpretation on behavioral and cognitive changes within organisations is weaker in individualistic than in collectivist national cultures.

\section{Masculinity}

The third national cultural dimension to be examined in this study is masculinity, which refers to the extent to which the dominant values in a society are "masculine" rather than "feminine." Hofstede (1980:47) elucidated that the defining characteristics of a masculine culture include competiveness and assertiveness, whereas a feminine national culture values people and relationships. Individuals in a masculine culture are more ambitious and voracious for wealth and material possessions. In the organisational settings, employees with a masculine cultural background are more performance- 
oriented, and pay less attention to building interpersonal relationships in the work place.

Although existing research on the effects of masculine culture on organisational learning is scarce, a few studies have shed light on how the masculinity dimension of a national culture could influence organisational knowledge transfer and collaboration. Ford and Chan (2003: 15) suggest that the masculinity level of a national culture is negatively related to knowledge sharing between organisational members. Further, Couto and Vieira (2004) found that cultures of low masculinity provided more support to collaboration, which led to a greater level of research and development activities within organisations. These studies suggest that as a high masculine culture places a greater emphasis on individual achievement and competition over interpersonal collaboration and relationship building, it would hinder individual's learning process that entails peer-to-peer information seeking and knowledge sharing. Therefore, organisational members in a masculine culture are less likely to engage in collaborative information seeking and quality information interpretation. Consequently, they are less likely to make behavioral and cognitive changes based on the information they have learned and interpreted. Hence, we propose the following hypotheses:

Hypothesis 4a: The impact of information acquisition on information interpretation within organisations is weaker in national cultures with high masculinity than with low masculinity.

Hypothesis 4b: The impact of information interpretation on behavioral and cognitive changes within organisations is weaker in national cultures with high masculinity than with low masculinity.

\section{Uncertainty avoidance}

Uncertainty avoidance is defined as the extent to which a society feels threatened by ambiguous situations and tries to avoid uncertainty by providing greater career stability, establishing more formal rules, circumventing deviant ideas and behaviors, and upholding absolute truths and the attainment of expertise (Hofstede 1980: 45). With regard to the effects of uncertainty avoidance on the development of organisational learning culture, one can expect two conflicting agendas. On the one hand, a high uncertainty avoidance culture provides well-defined responsibilities for information processing and makes effective decisions on what information to be acquired, who is responsible for information interpretation, and how to make cognitive and behavioral changes based on information learned. On the other hand, a high uncertainty avoidance culture diminishes the flexibility, creativity and innovation in information learning. In effect, the learning process in a low uncertainty avoidance national culture is developed in a more efficient and flexible fashion (Wilkesmann et al. 2009). 
In light of today's global competition that values innovations and changes, we speculate that a high uncertainty avoidance culture would bring adverse influence on the development of organisational learning culture. When organisations and their employees are hesitant to embrace uncertainty and ambiguity, they are less motivated to acquire new information and seek unconventional ways to interpret such information. They are inclined to follow pre-existing rules and protocols to process information. Further, they are less likely to make behavioral and cognitive changes to avoid risks and maintain stability. In contrast, organisational members from a low uncertainty avoidance culture are more flexible and active in seeking new information, engage in experimental learning, and even learning from failure (Madsen/Desai 2010). They have greater propensity to change their perceptions and behaviors to adapt to the constantly changing environment. Therefore, given the increasing level of uncertainty and ambiguity in the information environment surrounding today's organisations (Brown/Duguid 2000), a high uncertainty avoidance culture would diminish the development of organisational learning culture. Thus we propose the following hypotheses (a summary of all hypotheses is provided in Figure 1):

Hypothesis 5a: The impact of information acquisition on information interpretation within organisations is weaker in national cultures with high uncertainty avoidance than with low uncertainty avoidance.

Hypothesis 5b: The impact of information interpretation on behavioral and cognitive changes within organisations is weaker in national cultures with high uncertainty avoidance than with low uncertainty avoidance.

\section{Figure 1: A multilevel model of organisational learning}

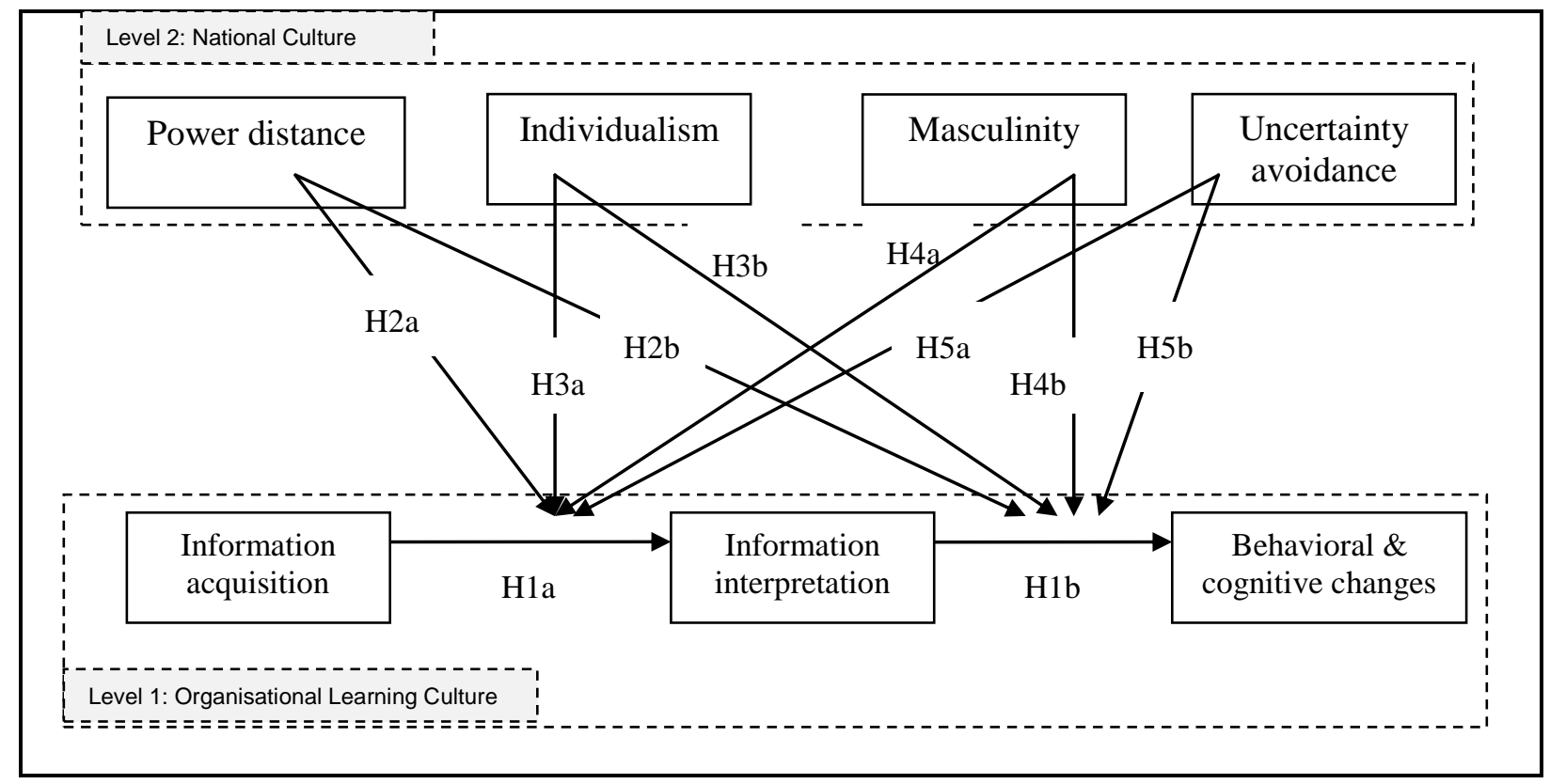




\section{Methods}

\section{Sample and procedures}

Empirical data were collected through surveys from 1333 companies with a size of 50 employees and larger. These companies were located in 7 countries across Europe and Asia: Slovenia, Croatia, Malaysia, Macedonia, South Korea, Spain, and Turkey, which all exhibit great variability in each of the four national cultural dimensions. We selected participating organisations from a diversified industrial background in order to enhance the external generalizability of this study. Surveys were distributed to managers at different levels and who were knowledgeable of the organisational culture and practices within their companies. In each company, only one participant answered our survey questions about the development of organisational learning culture in his/her company.

Adapted from the OLIMP (Organisational Learning and Information Management Processes) questionnaire developed in previous research on organisational learning culture (Dimovski/Škerlavaj 2008; Škerlavaj et al. 2007), the original version of our survey was created in English. Then the survey was translated into seven official languages (Slovenian, Croatian, Korean, Spanish, Macedonian, Turkish, and English for Malaysia) prior to be distributed. We administered the data collection by collaborating with local research teams in each of the seven counties. All team members were familiar with the goals of this study, and were proficient in both English and their local official language. The overall response rate was $31.4 \%$ across all countries. Table 1 summarizes the major demographic characteristics of participating companies. 


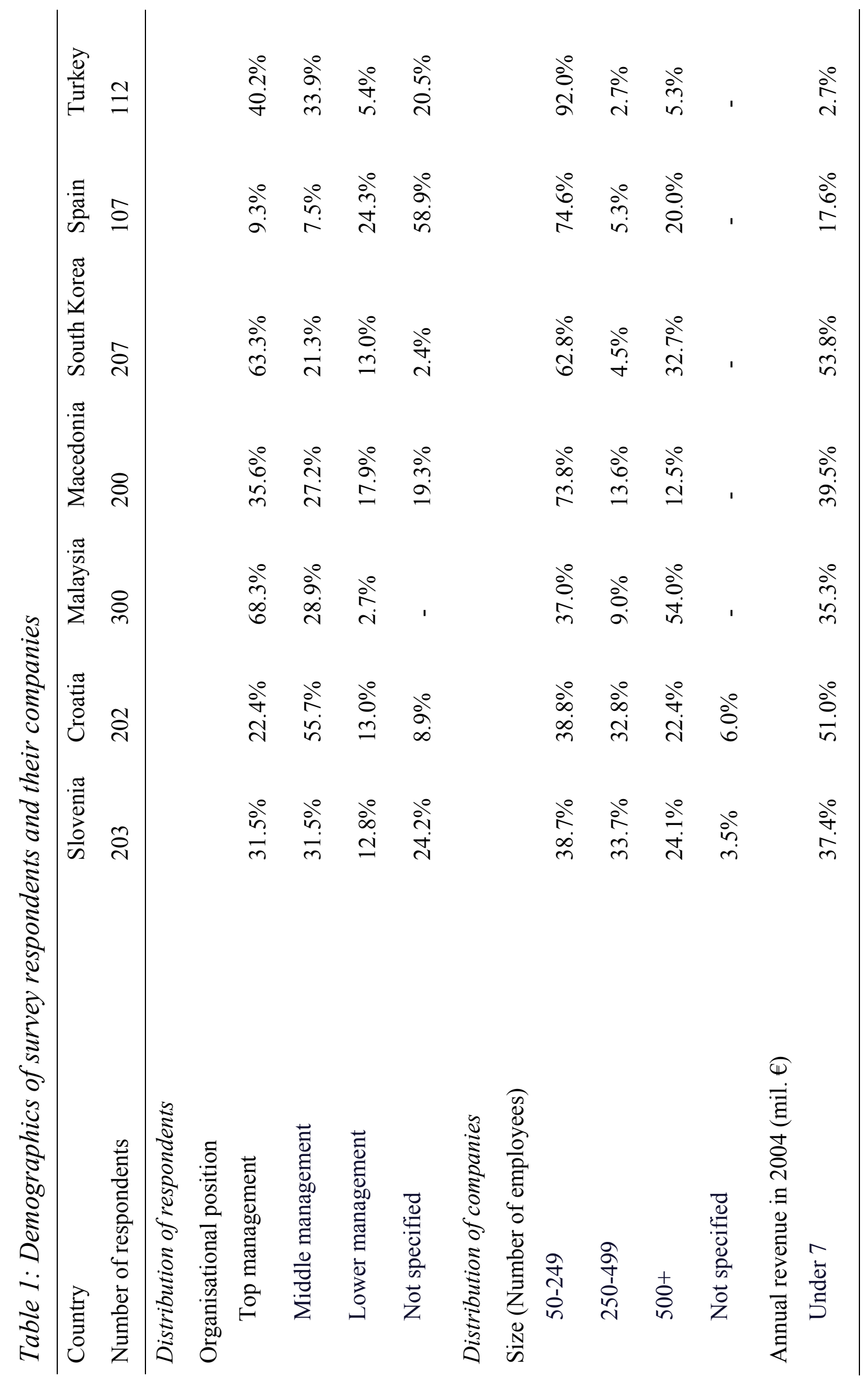




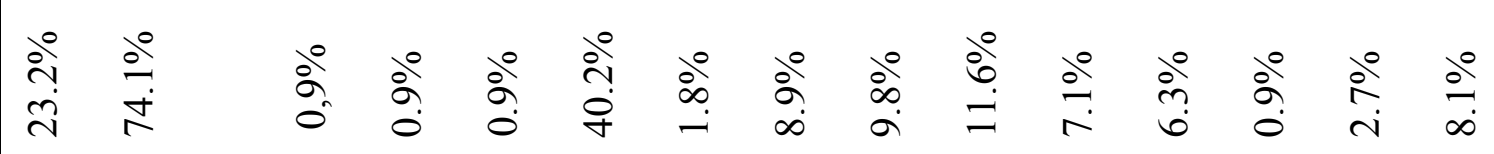

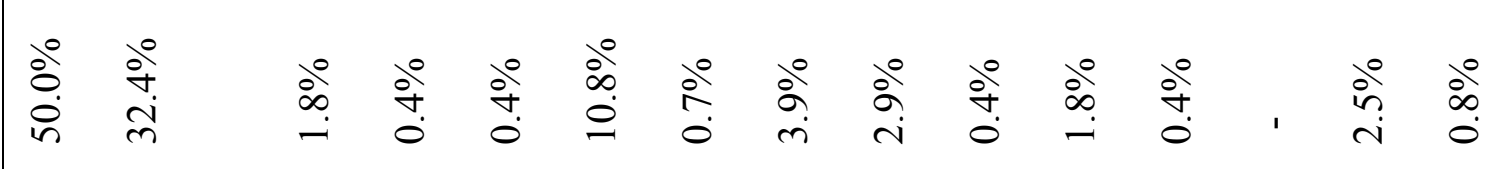

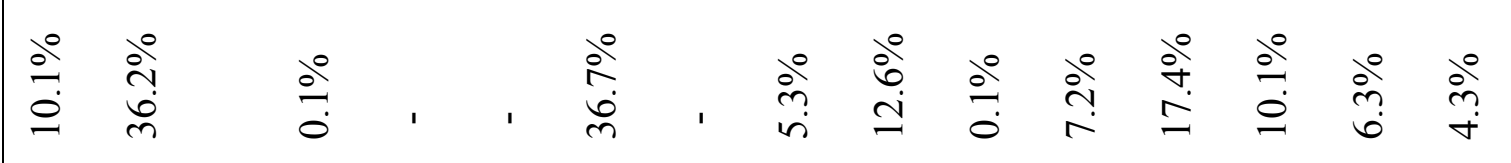

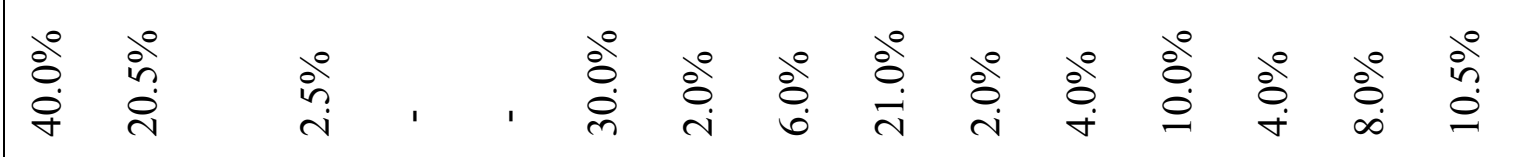

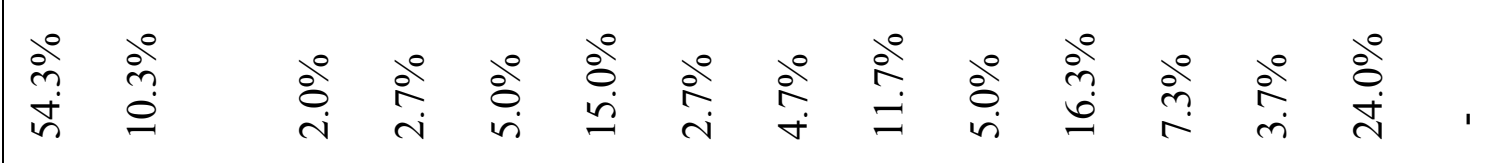

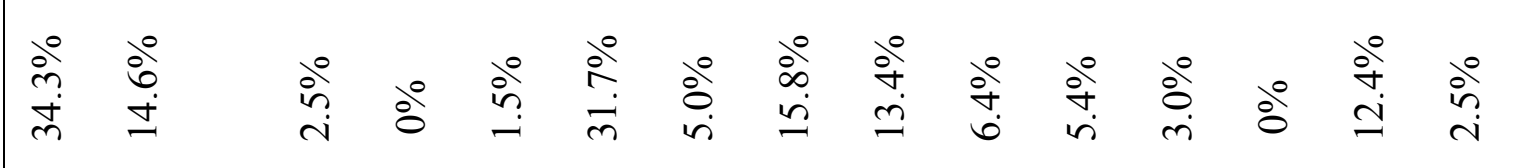

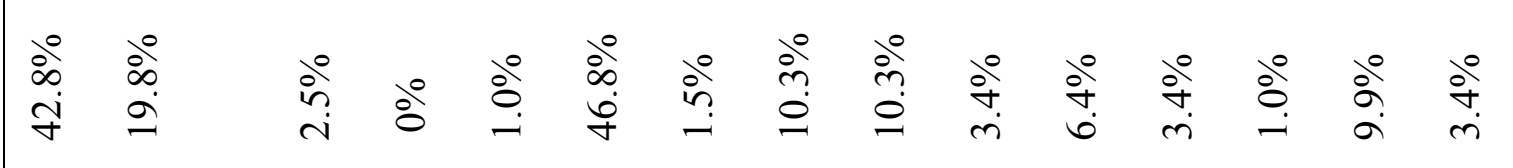

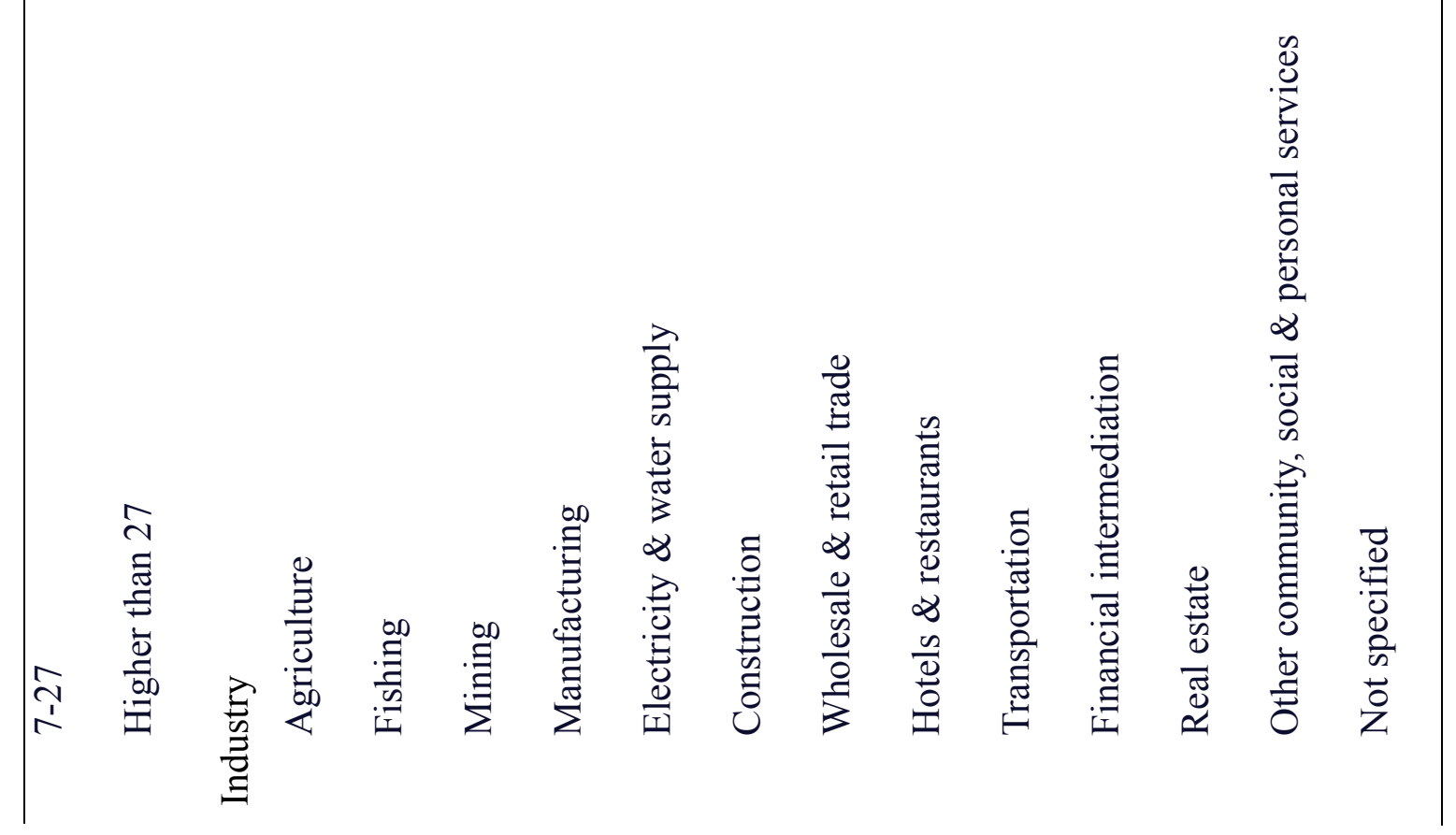




\section{Measures}

The data of this study comes from two sources. The data for testing the development of organisational learning culture were collected in the surveys mentioned above. The measures of the three key variables of organisational learning (information acquisition, information interpretation, and behavioral and cognitive changes) were adapted from previous research on organisational learning culture (Dimovski/Škerlavaj 2008; Škerlavaj et al. 2007). The second set of data concerns 4 national cultural dimensions, which was retrieved from Hofstede's models of national cultures and cross-cultural differences (Hofstede 2001; Hofstede/Hofstede 2005).

While there are heated debates about the common method variance (Spector 2006; Vandenberg 2006), majority of researchers agree that common method variance (i.e., variance that is attributable to the measurement method rather than to the constructs the measures represent) is a potential problem in behavioral research (e.g. Chang/van Witteloostuijn/Eden 2010; Colquitt/Ireland 2009; Podsakoff/MacKenzie/Lee/Podsakoff 2003). While it varies for different disciplines, approximately one quarter of the variance (Cote/Buckley 1987) can be contributed to the influence of prior pattern of responses on the responses to certain survey item (Colquitt/Ireland 2009). While this is a major concern for most authors, reviewers and editor of journals publishing empirical contributions in management, psychology, sociology, business and education, there are also some remedies to it. Various authors (Burton-Jones 2009; Chang et al. 2010; Podsakoff et al. 2003) suggest both statistical and procedural methods of control in order to minimize effect of the common method variance to the overall quality of data gathered.

In order to avoid problems with common method bias we used several approaches. First, we have used data from two different sets of sources: 1) OLIMP questionnaire (Škerlavaj et al. 2007) and 2) Hofstede's research on national culture (Hofstede 2001). Therefore, none of the hypotheses related to moderating effects of national cultures should be affected by this source of variance. Second, following suggestions and applications in the literature (e.g. Murray/Kotabe/Zhou 2005) we used some reverse coded items for the organisational learning constructs (information acquisition, information interpretation, and behavioral and cognitive changes). Third, we employed Harman's one factor test on three organisational learning constructs to post-hoc address the common method variance issue. If that was a severe difficulty in our study, one would expect a single factor to emerge for exploratory factor analysis or one factor to account for most of the covariance in the independent and criterion variables (Murray et al. 2005; Podsakoff/Organ 1986). Our exploratory factor analysis on organisational learning culture items results showed no general factor was evident in the unrotated factor structure, with Factor 1 accounting only for $21.0 \%$ of the variance. Thus, both preemptive procedural 
(data collection design) as well as post-hoc statistical measures suggest that common method variance is not a problem.

\section{Information acquisition}

A set of 15 items was used to measure information acquisition based on a 5point Likert-type scale ranging from $1=$ "strongly disagree" to $5=$ "strongly agree." These items assessed the degree to which the organisation supports and values the provision of quality information, active seeking of advice and new business methods, and acquisition of knowledge related to the operation of the company. Examples of the items include "In our organisation we explicitly reward employees who are a source of quality information" and "Expertise regarding the industry, products, and services is an extremely important criterion for hiring a new employee." The full description of the survey instrument is available from the first author of this paper.

\section{Information interpretation}

The measurement of information interpretation consisted of 11 items. The first nine items asked participants to rate the importance of information interpretation through a selection of communication means (e.g. personal contacts, team meetings, committees as decision-makers, telephone calls, special reports, emails, intranets, and electronic forums) within the company. The last two items asked participants to rate the importance of information sharing between the management and subordinates, and the simplicity and conciseness of such information. An example of the item is "For information interpretation and the recognition of business opportunities the following things are important: team meetings." The measurement of each item was based on a 5-point scale ranging from 1= "not important at all" to 5= "very important."

\section{Behavioral and cognitive changes}

This variable was measured by a set of 14 items in the survey. Each participant was asked to report the degree of changes that took place in 14 different areas of organisational practices in the company within the last three years. These areas included the quality of products/services, number of products/services offered, speed of operations, introduction of new marketing approaches, efficiency of information systems within the company, level of understanding of major problems in the company, and level of understanding of company's strategic orientation. Each item was measured on a 5-point scale ranging from $1=$ "substantial decline/decrease" to $5=$ "substantial improvement/increase."

\section{National culture}

We acquired the data of the four national cultural dimensions from three external sources. The national culture data for Croatia, Malaysia, South Korea, Spain, and Turkey were directly retrieved from Hofstede's research (Hofstede 
2001; Hofstede/Hofstede 2005). Hofstede reported scores of each national cultural dimension for over 70 countries and regions based on his initial research on IBM employees from 40 countries and subsequent replications and extensions on other international populations all over the world. Since Hofstede's works focused on former Yugoslavia, we retrieved the national culture scores from more recent research for Slovenia (Jazbec 2007) and Macedonia (Avramska 2007). Both studies utilized the same criteria Hofstede used in evaluating the national cultural dimensions. Based on empirical research, they provided more accurate and precise cultural scores for these two countries. Across all seven countries, the range of the scores in each of the four national cultural dimensions was: power distance (ranging from 27 to 104), individualism (ranging from 18 to 107), masculinity (ranging from 20 to 86), and uncertainty avoidance (ranging from 8 to 42 ).

\section{Results}

\section{Descriptive statistics}

Table 2 provides descriptive statistics of all variables analyzed in this study, including the means, standard deviations, and inter-correlations. The inter-item reliability coefficients are reported on the diagonal of the correlation matrix in Table 2. 


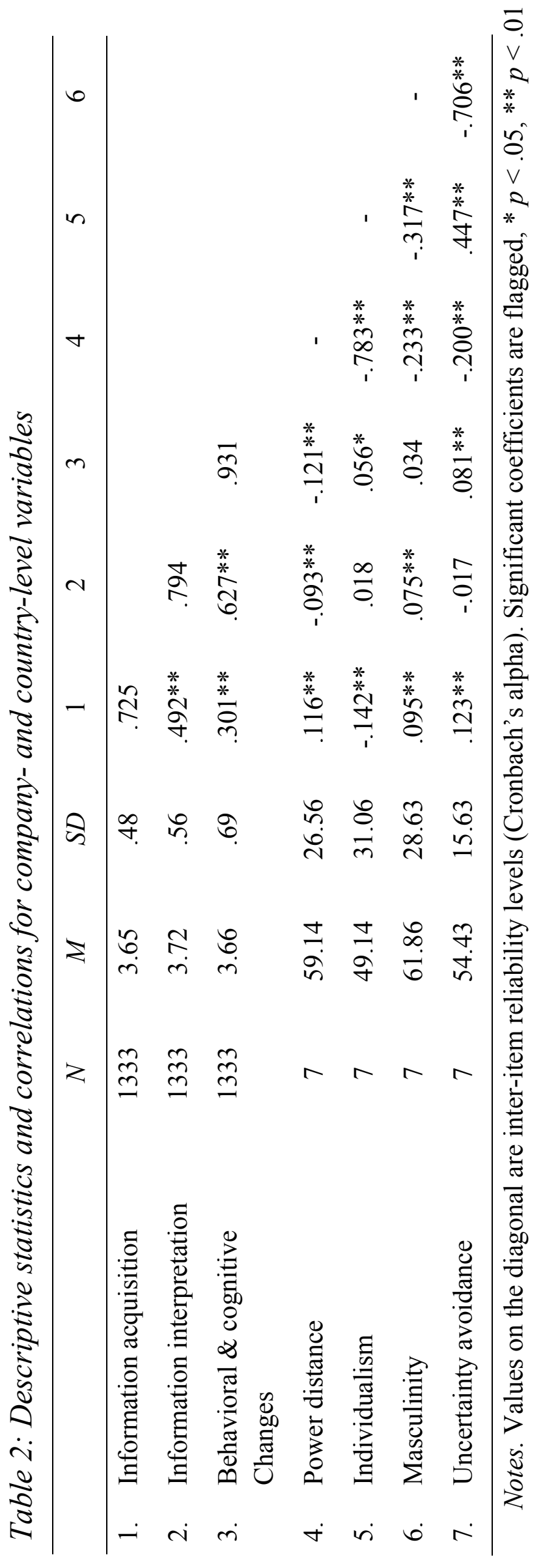




\section{Multilevel models and component evaluation}

The dataset consisted of two hierarchically nested levels: 1333 organisations (level-1) nested within 7 countries (level-2). In each of the 1333 organisations, one participant provided data on the information acquisition, information interpretation, and behavioral and cognitive changes in his/her company. These data constituted the lower-level unit of analysis in this study. The second-level data included the four national culture scores for each of the seven countries. Therefore, we used Hierarchical Linear Modeling (HLM 6.0, Raudenbush/Bryk 2002) to test the following aspects of our multilevel model of organisational learning: 1) the existence of a multilevel structure, 2) the moderating effects of each cultural dimension on the relationship between information acquisition and information interpretation, and 3) the moderating effects of each cultural dimension on the relationship between information interpretation and behavioral and cognitive changes.

\section{Testing the existence of a multilevel structure}

As suggested by Raudenbush and Bryk (2002), this study first tested the existence of a multilevel structure in the model we proposed. In the interceptonly model with information interpretation as the dependent variable, the ICC (intraclass correlation) at the national level (level-2) was .085, which indicates a high degree of association on information interpretation behaviors between different organisations within the same nation. In other words, organisations from the same country in our study perceived a similar level of importance in information interpretation within the organisation. Following Hayes' (2006) recommendation to use multilevel modeling in situations where intraclass correlations exceed 0.05 , the ICC results of the intercept-only model justified our use of a multilevel analysis as an appropriate strategy for analyzing the effects of information acquisition on information interpretation. In the interceptonly model with behavior and cognitive changes as the dependent variable, the ICC at the national level (level-2) was .033, indicating a relatively low degree of association on behavioral and cognitive changes between organisations within each country. However, as Hox (2002) suggests, the low intraclass correlations at higher levels could be offset by the large cluster sizes at those levels. As our study examined a large number of organisations (190 companies on average) in each country, the multilevel analysis procedure is still an appropriate method for testing the influence of information interpretation on behavioral and cognitive changes.

\section{Incremental model building: Information interpretation as the dependent variable}

To test our hypotheses, we developed two sets of multilevel models based on the theoretical predictions using the incremental improvement procedure outlined by Hox (2002: 49-71). In the construction of these models, all variables were 
grand-mean centered. The estimated coefficients and standard errors for all models are presented in Table 3 and Table 4.

First, to test the influence of information acquisition on information interpretation (H1a) and the moderating effects of each cultural dimension on such relationship (H2a, H3a, H4a, and H5a), we started with the intercept-only model with information interpretation as the dependent variable (see Model 1 in Table 3). Then we added information acquisition as a level-1 explanatory variable (Model 2), and found Model 2 significantly improved on the interceptonly model. Finally, we added each of the four national cultural dimensions to Model 2 separately (Model 3a, 3b, 3c, and 3d). The results showed that, compared to Model 2, the overall model fit for each of the four incremental models (with the national-level variables added) significantly deteriorated ( $\Delta$ Deviance $=353.80,-13.74,-13.56,-13.12,-11.92$ respectively, $p<.01$, see Table 3). The results suggested that none of the interaction effects between each national cultural dimension and information acquisition contributed to explaining information interpretation above and beyond information acquisition.

To directly test the effects of information acquisition on information interpretation (H1a) and how this relationship could be moderated by each of the four national cultural dimensions: power distance $(\mathrm{H} 2 \mathrm{a})$, individualism $(\mathrm{H} 3 \mathrm{a})$, masculinity (H4a), and uncertainty avoidance (H5a), we examined the coefficients of the corresponding parameters estimated in the models mentioned above. First, as shown in Table 3, at the organisational-level (level-1), information acquisition was found to be positively related to information interpretation (Model 2, $\gamma=.58, S E=.03, p<.01$ ). Thus H1a was supported. However, at the national level (level-2), none of the four national cultural dimensions (Model 3a-3d) had a significant effect on the relationship between information acquisition and information interpretation, thus $\mathrm{H} 2 \mathrm{a}, \mathrm{H} 3 \mathrm{a}, \mathrm{H} 4 \mathrm{a}$, and H5a were not supported. Taken together, these results suggest that while ascribing greater importance to information acquisition would lead to a greater perception of the importance in information interpretation overall, such influence was not affected by a specific national cultural dimension in each of the seven countries. 


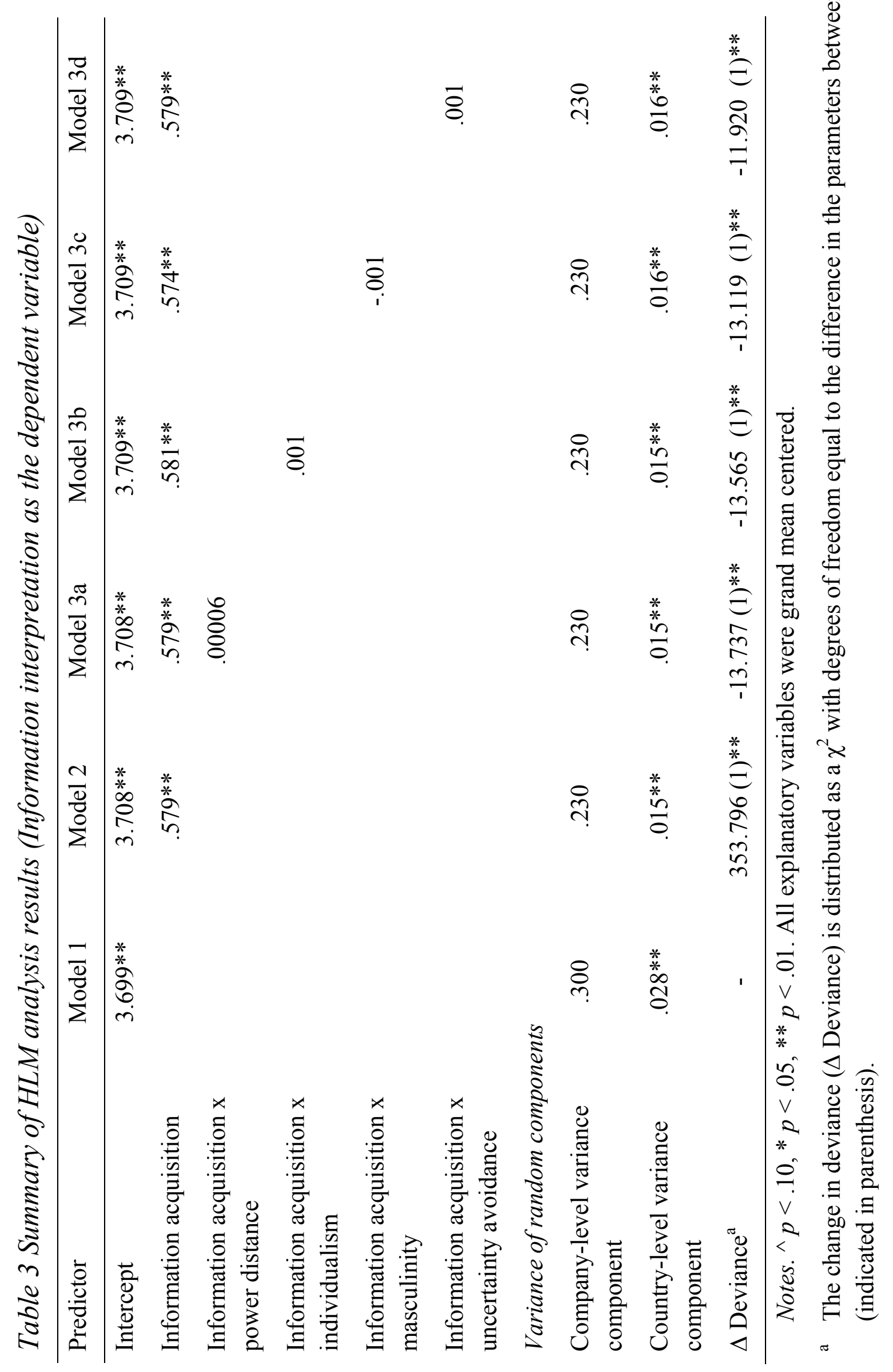




\section{Incremental model building: Behavioral and cognitive changes as the dependent variable}

To test the second set of hypotheses (H1b, H2b, H3b, H4b, and H5b), we began with an intercept-only model in which behavioral and cognitive changes was the dependent variable (see Model 4 in Table 4). Then we added information interpretation as a level-1 explanatory variable (Model 5), and found the new model significantly improved on the intercept-only model. Finally, we added each of the four national-level variables to Model 5 separately (Model 6a, 6b, $6 \mathrm{c}$, and $6 \mathrm{~d})$. The results showed that each of these incremental models significantly improved over Model $5(\Delta$ Deviance $=657.23,177.63,77.73$, $35.19,6.04$ respectively, $p<.01$, see Table 4$)$.

As the model-fit increased with adding the cross-level interaction effects, we examined the coefficients of the corresponding parameters to assess the direct effects of information interpretation on behavior and cognitive changes (H1b), as well as how this relationship could be moderated by power distance $(\mathrm{H} 2 \mathrm{~b})$, individualism $(\mathrm{H} 3 \mathrm{~b})$, masculinity $(\mathrm{H} 4 \mathrm{~b})$, and uncertainty avoidance $(\mathrm{H} 5 \mathrm{~b})$. As shown in Table 4, at the organisational-level (level-1), information interpretation was found to be positively related to behavioral and cognitive changes (Model 5, $\gamma=.78, S E=.03, p<.01)$. Thus H1b was supported.

Further, at the national level (level-2), each of the four national cultural dimensions had a significant effect on the relationship between information acquisition and information interpretation. However, contrary to $\mathrm{H} 2 \mathrm{~b}$, the power distance dimension had a positive effect on the relationship between information interpretation and behavioral and cognitive changes (Model 6a, $\gamma=.01, S E=$ $.001, p<.01)$. In addition, individualism was found to have a negative impact on the relationship between information interpretation and behavioral and cognitive changes (Model 6b, $\gamma=-.01, S E=.001, p<.01$ ), which supported H3b. Similarly, consistent with $\mathrm{H} 4 \mathrm{~b}$ and $\mathrm{H} 5 \mathrm{~b}$, the masculinity and uncertainty avoidance dimensions had a significant negative effect on the relationship between information interpretation on behavioral and cognitive changes (Models $6 \mathrm{c}$ and $6 \mathrm{~d}, \gamma=-.01, S E=.001, p<.01)$. These results suggest that in the presence of the positive influence of information interpretation on behavioral and cognitive changes within organisations, such influence is weakened by the level of individualism, masculinity and uncertainty avoidance, and strengthened by the level of power distance in the national culture. 


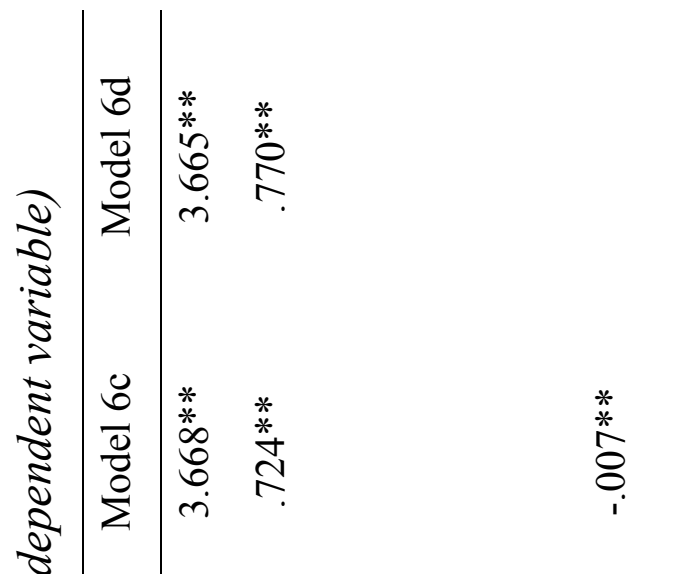

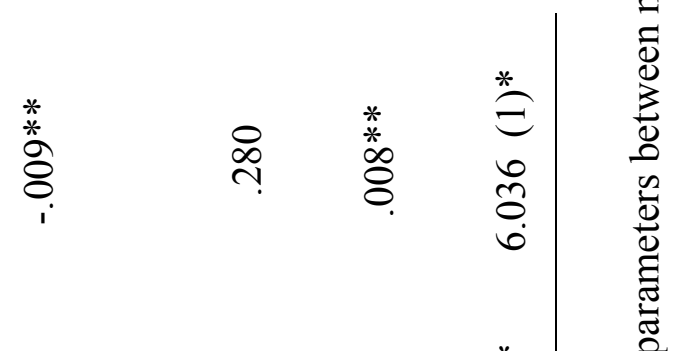

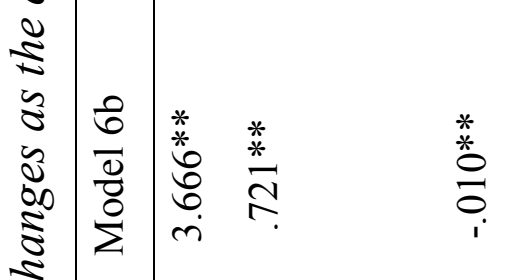

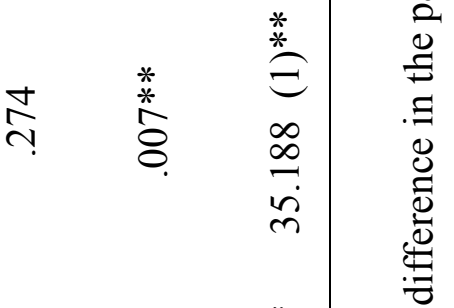

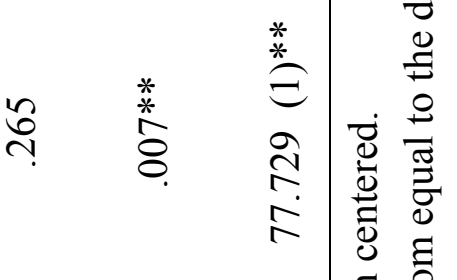

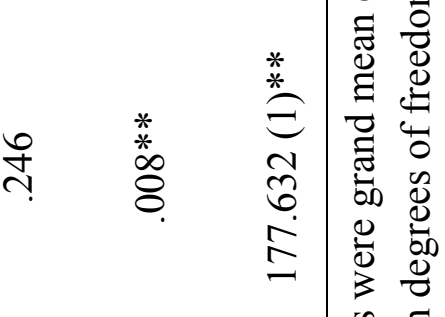

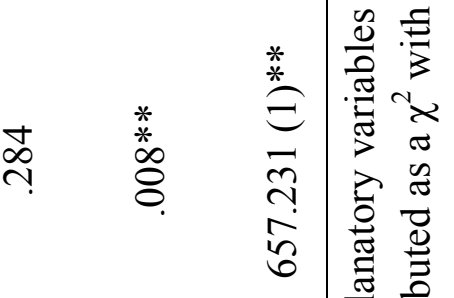

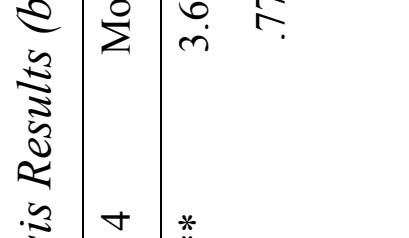

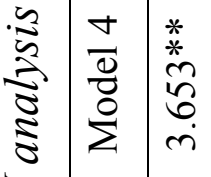

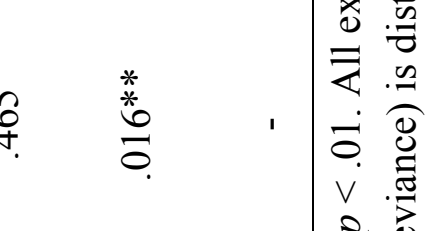

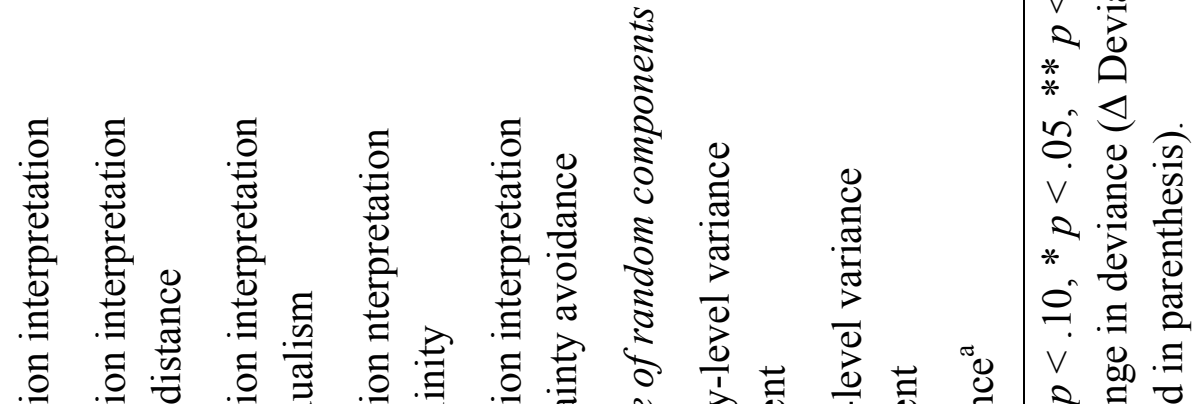

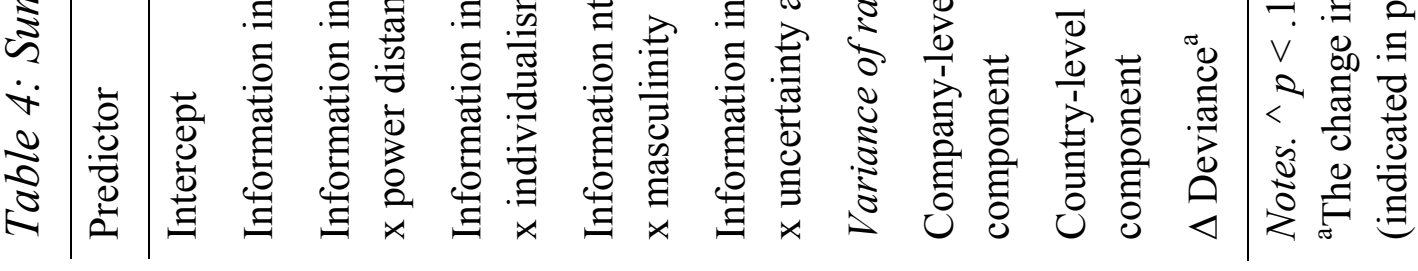




\section{Discussion}

The goal of this study was to theorize and empirically test a multilevel model of the moderating effects of national cultural dimensions on the development of organisational learning culture. Specifically, we developed two sets of multilevel hypotheses to examine the degree to which each of the four primary national cultural dimensions would enhance or weaken the previously established positive relationships between information acquisition, information interpretation, and behavioral and cognitive changes (e.g. Škerlavaj et al. 2007). By using hierarchical linear modeling analysis of empirical data collected from 1333 organisations across seven countries, we found support for cross-level interaction effects between national cultural dimensions and the positive influence of information interpretation on behavioral and cognitive changes. In the models where behavioral and cognitive changes were the dependent variable models, the improvement of model-fit after the inclusion of national-level variables has demonstrated the viability and importance of using a multilevel approach to studying the development of organisational learning culture. The findings from this study provide further support to the conceptualization of organisational learning as a multilevel and context-based process (Holmquist 2004; Huber 1991; Ibarra et al. 2005; Quigley/Tesluk/Locke/Bartol 2007). Thus it is imperative to examine organisational learning processes not only within the organisational boundary, but within a specific national cultural context and even cross-cultural settings as well.

The foundation of this study is built upon the sequential relationships between three key elements in the development of organisational learning culture: perceived importance of information acquisition leads to greater perceived importance in information interpretation, and consequently a greater level of behavioral and cognitive changes. A number of research studies have provided theoretical and empirical support to the establishment of these fundamental linkages in organisational learning (see Hernaus et al. 2008; Mok Kim Man et al. 2007; Škerlavaj/Dimovski 2009; Škerlavaj et al. 2007; Zagoršek et al. 2009). By analyzing data from organisations located in 7 geographically and culturally distinct countries, this study replicated and generalized previous research findings to a broader international population. Overall, organisations that place greater emphasis on information acquisition tend to emphasize more on the importance of information interpretation, which leads to greater behavioral and cognitive changes.

The major contribution of this study is to investigate a higher-level contextual influence on organisational learning: how national cultural dimensions moderate the positive influence of information acquisition on information interpretation, and that of information interpretation on behavioral and cognitive changes. Contrary to what this study hypothesized, there was no significant moderating effect of any of the four national cultural dimensions on the relationship between 
information acquisition and information interpretation. Such findings suggest that national cultures play an insignificant role in moderating the initial development of organisational learning culture. In other words, organisations' emphasis on the importance of information interpretation is universally influenced by their perceptions of the importance in information acquisition. Such effects would not be strengthened or weakened by the level of power distance, individualism, masculinity, or uncertainty avoidance in a specific national culture. However, the lack of moderating effects of these four cultural dimensions in this phase does not exclude the existence of other moderators at the national or organisational level. At the national culture level, the fifth cultural dimension developed by Hofstede, long term orientation, might exert a moderating effect on the positive influence of information acquisition on information interpretation. One can speculate that organisations in a long-term oriented culture are more likely to emphasize on the importance of information interpretation, whereas organisations in a short-term oriented culture tend to focus more on the acquisition of large quantity of information rather than an indepth and enduring interpretation of such information. At the organisational level, the relationship between information acquisition and interpretation could be moderated by contextual factors such as organisational structures (Rulke/Galaskiewicz 2000), absorptive capacity of employees (Tsai 2001), and the intrinsic characteristics of organisational knowledge to be learned (Zander/Kogut 1995).

The key finding of this study is the interaction effects of national culture dimensions on the positive relationship between information interpretation and behavioral and cognitive changes. A crucial outcome of the development of organisational learning culture is the modification of behaviors (Madsen/Desai 2010) and cognitive beliefs (Crossan et al. 1999) based on the interpretation of information acquired. Our study found that each of the four national cultural dimensions played a significant role in moderating how information interpretation led to greater behavioral and cognitive changes. In particular, the positive influence of information interpretation on behavioral and cognitive changes was strengthened by power distance and weakened by individualism, masculinity, and uncertainty avoidance in a specific national culture. These finding suggest that while the perceived importance of information interpretation as a result of information acquisition is unaffected by the national cultural context in general, the process of converting interpreted information into action could be facilitated or hindered by a specific national cultural dimension.

It is worth noting that while the moderating effect of the power distance dimension was found to be significant, it worked in the opposite direction as to what we hypothesized $(\mathrm{H} 2 \mathrm{~b})$. It suggests that the greater acceptance of the inequality of power distribution within organisations, the greater influence 
information interpretation would have on employees' behavioral and cognitive changes. In other words, organisational members in a high power distance culture are more likely to modify their behaviors and perceptions when they perceive a greater level of importance in information interpretation. We speculate that such tendency is related to the increasing emphasis on knowledge transfer and information utilization in today's knowledge-based economy. In those cultures where members are more likely to accept and expect the power to be distributed unequally, they are also willing to conform to managerial control and modify their behaviors according to corporate values. As more companies incorporate intra-organisational knowledge sharing and learning into formal corporate procedures and rules, those members who are more acceptable to power distance are more likely to make behavioral and cognitive changes so that they can adapt to the organisational learning culture. In contrast, for those members who are less tolerant of the managerial control, they would be more likely to act independently and differently from the organisational learning culture. Thus in organisations situated in a high power distance culture, employees are even more likely to transform their interpretations of information into behavioral and cognitive modifications, because such changes might be required by the management or conform to organisational culture and values.

Consistent with our predictions, the positive effect of information interpretation on behavioral and cognitive changes was negatively affected by the level of individualism, masculinity, and uncertainty avoidance in a specific national culture. A defining characteristic of an individualistic culture is its predominant preference of individual goals and interests over collective goals and interests. Given the social nature of organisational learning rendered by social learning theory (Bandura 1969), it is not surprising to find the hampering effect of individualism on organisational members' behavioral and cognitive changes as a result of information interpretation. In addition, according to theories of mutual interest and collective action (Coleman 1973, 1990), organisational learning is a coordinated process that produces outcomes unattainable through individual actions alone (Monge/Contractor 2003). Therefore, it is reasonable to expect that a national culture that stresses the importance of individual values and actions would weaken the positive impact of information interpretation on behavioral and cognitive changes.

Masculinity is another dimension of national culture that negatively affects the development of organisational learning culture. The inherent values of a masculine culture emphasize on the achievement of short-term material goals while caring less for interpersonal relationships and long-term development. As such, members of a masculine culture are more likely to make behavioral and cognitive changes for purposes such as profit generation and self-promotion, rather than relationship building and cultivating a learning culture. Given the well-established connection between organisational learning and organisational 
performance, our study suggests that organisations of a masculine culture may be able to attain satisfactory performance and profits in the short term, but would encounter greater challenges and difficulties in developing a positive organisational learning culture which is required for their sustainable growth. Similarly, as the uncertainty avoidance dimension would weaken the influence of information interpretation on behavioral and cognitive changes, the organisational learning culture is more likely to be cultivated in an organisation that embraces changes and uncertainty. In low uncertainly avoidance cultures, organisational members are willing to modify their behaviors and perceptions to reflect what they have learned from the information environment. The pursuit of new information and openness for changes in such cultural contexts would ultimately lead to more innovative learning processes and a healthy organisational learning culture.

\section{Theoretical contributions}

This study contributes to existing research on organisational learning in the following aspects. First, we develop a multilevel theoretical model of organisational learning that examines the moderating effects of national cultural dimensions on the sequential relationships of information acquisition, information interpretation, and behavioral and cognitive changes. Our study advances previous research on organisational learning culture by not only finding support for the direct effects of organisational-level explanatory variables, but more importantly, by capturing the moderating effects of nationallevel contextual variables. The results of this study confirm the viability and importance in including the national cultural dimensions in the theoretical development of organisational learning. Second, unlike previous research on related topics that relied solely on case studies or conceptual reasoning, we tested our theoretical models of organisational learning with empirical data. This approach resonates a recent call for more rigorous empirical testing of theories in organisational culture research (Yammarino/Dansereau 2010). Given the nesting structure of our theoretical models, a multilevel analysis is most appropriate for testing cross-level interaction effects in organisational learning research. To the best of our knowledge, this is the first study that utilizes the multilevel analytic procedure to study how national cultural dimensions influence the organisational learning culture. The multilevel approach helps provide an enriched understanding of the contextual influences of national cultures on organisational learning culture, which has been traditionally examined at the organisational level only. Third, this study examines data from seven countries across Asia and Europe, and each of these nations represents a distinct national and cultural background. Moreover, our participating organisations come from a wide range of industries. The number and diversity of organisations we examined in this study enable us to generalize the findings of this research to a broader organisational and national context. 


\section{Practical implications}

The findings of this study encourage managers to how to remain competitive in a globalized economy by leveraging cultural diversity in the development of organisational learning culture. An important message for organisational managers is that they should seek to balance the strengths and weaknesses of cultural diversity in order to better facilitate knowledge transfer and organisational learning to support productive work on a global stage.

Another key practical implication of our study is that managers should be mindful of the potential negative impact of certain cultural dimensions on organisation learning. For example, for organisations saturated in individualistic cultures, managers should cultivate a working environment that values peer-topeer information sharing and knowledge transfer. They should establish organisational procedures and rules to prevent individuals from holding information to serve their own interests, and should implement organisational incentives to reward collective learning and information sharing. For employees working in a high uncertainty avoidance culture, organisations should design appropriate knowledge transfer systems to facilitate their efforts in information seeking and problem-solving. Examples of such systems include digital information databases and search engines on corporate intranets, which could simplify employees' information acquisition processes and consequently enhance their willingness to cope with organisational uncertainty by learning new information.

\section{Limitations and future research}

Although this study did not find a significant moderating effect of national cultural dimensions on the relationship between information acquisition and information interpretation, it by no means suggests that such a relationship is independent from other contextual variables at the organisational and national level. Actually, as mentioned in the results section of this paper, the high intraclass correlation (ICC) in modeling the effects of information acquisition on information interpretation (Model 1) implies that employees tend to interpret information in similar fashions within the same nation. Such results suggest that besides the four primary national cultural dimensions examined in this study, there may be other national and cultural variables that would contribute to the variation in information interpretation across different countries and the similarity of such behaviors within the same country. Future research should investigate additional contextual factors from internal and external environment to further understand the contextual influences on the development of organisational learning culture.

Additionally, there have been increasing debates about the validity and reliability of Hofstede's national culture scores (Holden 2002; McSweeney 2002; Wilkesmann et al. 2009; Williamson 2002). We developed our multilevel 
models based on Hofstede's cultural dimensions for two reasons. First, Hofsted's work is one of the most widely cited researches on cross-cultural differences (Chandy/Williams 1994; Kogut/Singh 1988; Michailova/Hutchings 2006), and his national cultural scores for over 70 countries and regions are publicly available. Second, few other research that reports national cultural scores is able to sustain validity over time and across different settings (Mouritzen/Svara 2002; Shane/Venkatraman 1996). Nonetheless, future research should explore national cultural dimensions established in other national culture models, such as the GLOBE project (House/Hanges/Javidan/Dorfman/Gupta 2004), Schwartz theory of cultural values (Sagiv et al. 2010; Schwartz 1999, 2004, 2009), and Trompenaars and Hampden-Turner's cultural dimensions (1998). Such endeavors would help uncover the cross-level interactions between organisational learning and other cultural variables not included in Hofstede's works. Finally, to further enhance the external generalizability of our study, additional research should be conducted to expand the scope of participating countries to include a broader range of national cultures from continents other than Europe and Asia.

\section{Conclusions}

This study develops a set of hypotheses to test the moderating effects of four national cultural dimensions on the development of organisational learning culture. Specifically, we seek to discover the cross-level interaction between national cultural dimensions and two key sequential relationships influencing organisational learning processes: the linkage from information acquisition to information interpretation, and the linkage from information interpretation to behavioral and cognitive changes. The results suggest that while national culture plays an insignificant role in influencing organisational employees' interpretation of information they have acquired, each of the four key cultural dimensions significantly strengthens or weakens the effects of information interpretation on behavioral and cognitive changes. Thus there is evidence that national culture plays a different role at different phases of the development of organisational learning culture. Furthermore, different cultural dimensions would influence organisational learning processes in different directions. Specifically, a high power distance culture would enhance the positive effects of information interpretation on behavioral and cognitive changes, whereas a high individualistic, masculine, and uncertainty avoidant culture would weaken and hinder such process.

Unlike majority of previous studies that examine national culture and organisational learning culture at separate levels, this study proposes an integrated theoretical framework to further understand how organisational learning culture develops within the national cultural context at large. This study demonstrates that the development of organisational learning culture is indeed a multilevel and context-based process. As all organisations operate within a 
specific national culture that is characterized by distinct cultural traits, organisational learning culture is inevitably influenced by these cultural dimensions. The multilevel model developed in this study contributes to existing literature by considering and incorporating the contextual influences of national cultu re on organisational learning.

\section{References}

Adler, N. J. (2002): International dimensions of organizational behavior (4th ed.). Cincinnati , $\mathrm{OH}$ : South-Western.

Arbaugh, J. B./Benbunan-Fich, R. (2006): An investigation of epistemological and social dimensions of teaching in online learning environments in: Academy of Management Learning \& Education, 5, 4, 435-447.

Argyris, C./Schön, D. A. (1996): Organizational learning II: Theory, method and practice. Reading, MA: Addison-Wesley.

Arthur, J. B./Huntley, C. L. (2005): Ramping up the organizational learning curve: Assessing the impact of deliberate learning on organizational performance under gainsharing, in: Academy of Management Journal, 48, 6, 1159-1170.

Avramska, I. (2007): Cross-cultural comparison between business students from Macedonia, Kosovo and Slovenia and cultural differences in relation to economic development. Unpublished Master's thesis, University of Ljubljana, Ljubljana, Slovenia.

Bandura, A. (1969): Social-learning theory of identificatory processes. in: D. A. Goslin (Ed.), Handbook on Socialization Theory and Research Chicago, IL: Rand Mc-Nally and Company, 213-262.

Bates, R./Khasawneh, S. (2005): Organizational learning culture, learning transfer climate and perceived innovation in Jordanian organizations, in: International Journal of Training \& Development, 9, 2, 96-109.

Bell, S. T. (2007): Deep-Level Composition Variables as Predictors of Team Performance: A Meta-Analysis, in: Journal of Applied Psychology, 92, 595-615.

Bhagat, R. S./Kedia, B. L./Harveston, P. D./Triandis, H. C. (2002): Cultural variations in the cross-border transfer of organizational knowledge: An integrative framework, in: Academy of Management Review, 27, 2, 204-221.

Bhattacharya, G. (1985): Strategic learning and entry-equilibrium, in: Journal of Economic Dynamics and Control, 9, 2, 195-224.

Brickson, S. L. (2007): Organizational identity orientation: The genesis of the role of the firm and distinct forms of social value, in: Academy of Management Review, 32, 3, 864888 .

Brown, J. S./Duguid, P. (2000): The social life of information. Cambridge, MA: Harvard Business School Press.

Burton-Jones, A. (2009): Minimizing Method Bias Through Programmatic Research, in: MIS Quarterly, 33, 3, 445-471.

Chandy, P./Williams, T. (1994): The impact of journals and authors on international business research: a citational analysis of JIBS articles, in: Journal of International Business Studies, 25, 4, 715-728. 
Chang, S.-J./van Witteloostuijn, A./Eden, L. (2010): From the Editors: Common method variance in international business research, in: Journal of International Business Studies 41, 178-184.

Chatman, J. A./Spataro, S. E. (2005): Using self-categorization theory to understand relational demography-based variations in people's responsiveness to organizational culture, in: Academy of Management Journal, 48, 321-331.

Chen, J./Sun, P. Y. T./McQueen, R. J. (2010): The impact of national cultures on structured knowledge transfer, in: Journal of Knowledge Management, 14, 2, 228-241.

Clark, E./Soulsby, A. (2009): Perceptions of MNC management: Local parent sensemaking in international joint venture process, in: Journal for East European Management Studies, $14,3,286-309$.

Coleman, J. S. (1973): The mathematics of collective action. Chicago, IL: Aldine.

Coleman, J. S. (1990): Foundations of social theory. Cambridge, MA: Harvard University Press.

Colquitt, J. A./Ireland, R. D. (2009): From the Editors: Taking the Mystery Out of AMJ's Reviewer Evaluation Form, in: Academy of Management Journal 52 2, 224 - 228.

Cote, J. A./Buckley, M. R. (1987): Estimating Trait, Method, and Error Variance: Generalizing across 70 Construct Validation Studies, in: Journal of Marketing Research, 24, 3, 315-318.

Couto, J. P./Vieira, J. C. (2004): National culture and research and development activities, in: Multinational Business Review, 12, 1, 19-36.

Crossan, M. M./Lane, H. W./White, R. E. (1999): An organizational learning framework: From intuition to institution, in: Academy of Management Review, 24, 3, 522-537.

de Geus, A. P. (1988): Planning as learning, in: Harvard Business Review, 88, March-April, 70-74.

Denison, D. R./Spreitzer, G. M. (1991): Organizational culture and organizational development: A competing values approach, in: Research in Organizational Change and Development, 5, 1-21.

Dimovski, V./Škerlavaj, M. (2008): Organizational learning as the key towards improved organizational performance. in: A. Koohang, K. Harman \& J. Britz (Eds.), Knowledge Management: Research and Application Santa Rosa, CA: Informing Science Press, 147-175.

Dimovski, V./Škerlavaj, M./Kimman, M./Hernaus, T. (2008): Comparative analysis of the organisational learning process in Slovenia, Croatia, and Malaysia, in: Expert Systems with Applications, 34, 4, 3063-3070.

Earley, P. C./Gibson, C. B. (1998): Taking stock in our progress on individualismcollectivism: 100 years of solidarity and community, in: Journal of Management, 24, 3, 265-304.

Easterby-Smith, M./Lyles, M. (2004): Introduction: The watersheds of organizational learning and knowledge management. in: M. Easterby-Smith \& M. Lyles (Eds.), Handbook of Organizational Learning and Knowledge Management Oxford, UK: Blackwell Publishing, 1-15. 
Egan, T. M./Yang, B./Barlett, K. R. (2004): The effects of organizational learning culture and job satisfaction on motivation to transfer learning and turnover intention, in: Human Resource Development Quarterly, 15, 3, 279-301.

Eisenberg, J. (1999): How individualism-collectivism moderates the effects of rewards on creativity and innovation: A comparative review of practices in Japan and the US, in: Creativity and Innovation Management, 8, 4, 251-261.

Fiedler, F. E. (1964): A contingency model of leadership effectiveness. in: L. Berkowitz (Ed.), Advances in Experimental Social Psychology New York: Academic Press.

Fiol, C. M./Lyles, M. A. (1985): Organizational learning, in: Academy of Management Review, 10, 4, 803-813.

Ford, D. P./Chan, Y. E. (2003): Knowledge sharing in a multi-cultural setting: A case study, in: Knowledge Management Research \& Practice, 1, 11-27.

Garvin, D. A. (1993): Building a learning organization, in: Harvard Business Review, 71, 4, 78-91.

Gupta, A. K./Govindarajan, V. (2000): Knowledge flows within multinational corporations, in: Strategic Management Journal, 21, 4, 473-496.

Hayes, A. F. (2006): A primer on multilevel modeling, in: Human Communication Research, $32,4,385-410$.

Hernaus, T./Škerlavaj, M./Dimovski, V. (2008): Relationship between organisational learning and organisational performance: The case of Croatia, in: Transformations in Business and Economics, 7, 2, 32-48.

Hersey, P./Blanchard, K. H. (1969): Life cycle theory of leadership, in: Training and Development Journal, 23, 5, 26-34.

Hocking, J. B./Brown, M./Harzing, A.-W. (2007): Balancing global and local strategic contexts: Expatriate knowledge transfer, applications, and learning within a transnational organization, in: Human Resource Management Journal, 46, 4, 513-533.

Hofstede, G. (1980): Motivation, leadership, and organizations: Do American theories apply abroad?, in: Organizational Dynamics, 9, 1, 42-63.

Hofstede, G. (1983): The cultural relativity of organizational practices and theories in: Journal of International Business Studies, 14, 2, 75-89.

Hofstede, G. (1984): The cultural relativity of the quality of life concept, in: Academy of Management Review, 9, 3, 389-398.

Hofstede, G. (1991): Cultures and organizations: Software of the mind. New York: McGrawHill.

Hofstede, G. (2001): Culture's consequences: Comparing values, behaviors, institutions and organizations across nations (2nd ed.). Thousand Oaks, CA: Sage.

Hofstede, G./Hofstede, G. J. (2005): Cultures and Organizations: Software of the Mind (2nd edition ed.). New York: McGraw-Hill.

Holden, N. J. (2001): Knowledge management: Raising the spectrum of cross-cultural dimension, in: Knowledge and Process Management, 8, 3, 155-163.

Holden, N. J. (2002): Cross-cultural management: A knowledge management perspective. Harlow, UK: Financial Times/Prentice Hall. 
Holmquist, M. (2004): Experimental learning processes of exploitation and exploration within and between organizations: An empirical study of product development, in: Organization Science, 15, 1, 15-32.

Hong, J. F. L./Easterby-Smith, M./Snell, R. S. (2006): Transferring organizational learning systems to Japanese subsidiaries in China, in: Journal of Management Studies, 43, 5, 1027-1058.

Hornik, S./Tupchiy, A. (2006): Culture's impact on technology mediated learning: The role of horizontal and vertical individualism and collectivism, in: Journal of Global Information Management, 14, 4, 31-56

House, R. J./Hanges, P. J./Javidan, M./Dorfman, P. W./Gupta, W. (2004): Culture, leadership and organizations: The GLOBE study of 62 societies. Thousand Oaks, CA: Sage.

Hox, J. J. (2002): Multilevel analysis: Techniques and applications. Mahwah, NJ: Lawrence Erlbaum.

Huber, G. P. (1991): Organizational learning: The contributing process and the literatures, in: Organization Science, 2, 1, 88-115.

Hwang, A./Francesco, A. (2010): The influence of individualism-collectivism and power distance on use of feedback channels and consequences for learning, in: Academy of Management Learning and Education Journal, 9, 2, in press.

Ibarra, H./Kilduff, M./Tsai, W. (2005): Zooming in and out: Connecting individuals and collectivities at the frontiers of organizational network research, in: Organization Science, 16, 4, 359-374.

Ilies, R./Wagner, D. T./Morgeson, F. P. (2007): Explaining Affective Linkages in Teams: Individual Differences in Susceptibility to Contagion and Individualism-Collectivism, in: Journal of Applied Psychology, 92, 1140-1148.

Jackson, C. L./Colquitt, J. A./Wesson, M. J./Zapata-Phelan, C. P. (2006): Psychological collectivism: A measurement validation and linkage to group member performance, in: Journal of Applied Psychology, 91, 884-899.

Jazbec, M. (2007): Slovenian national culture and cross-cultural training. in: J. Prasnikar \& A. Cirman (Eds.), New emerging economies and their culture New York: Nova Science Publishers, 57-71.

Kim, U./Triandis, H. C./Kagitcibasi, C./Choi, S.-G./Yoon, G. (Eds.). (1994): Individualism and collectivism: Theory, method and application. Newbury Park, CA: Sage.

Kirkman, B. L./Shapiro, D. L. (1997): The impact of cultural values on employee resistance to teams: Toward a model of globalized self-managing work team effectiveness, in: Academy of Management Review, 22, 3, 730-757.

Kogut, B./Singh, H. (1988): The effect of national culture on the choice of entry mode, in: Journal of International Business Studies, 19, 3, 411-432.

Kostova, T./Roth, K. (2002): Adoption of an organizational practice by subsidiaries of multinational corporations: Institutional and relational effects, in: Academy of Management Journal, 45, 1, 215-233.

Levitt, B./March, J. G. (1988): Organizational learning, in: Annual Review of Sociology, 14, 319-340. 
Madsen, P. M./Desai, V. (2010): Failing to learn? The effects of failure and success on organizational learning in the global orbital launch industry, in: Academy of Management Journal, 53, 3, in press.

McSweeney, B. (2002): The essentials of scholarship: A reply to Geert Hofstede, in: Human Relations, 55, 11, 1363-1372.

Mead, M. (1967): Cooperation and competition among primitive people. Boston, MA: Beacon.

Meyer, K. E. (2007): Contextualising organisational learning: Lyles and Salk in the context of their research, in: Journal of International Business Studies, 38, 1, 27-37.

Michailova, S./Hutchings, K. (2006): National cultural influences on knowledge sharing: A comparison of China and Russia, in: Journal of Management Studies, 43, 3, 383-405.

Mok Kim Man, M./Dimovski, V./Škerlavaj, M. (2007): The organizational learning in Malaysian companies, in: The Business Review, Cambridge, 9, 1, 112-118.

Monge, P. R./Contractor, N. S. (2003): Theories of Communication Networks. Oxford: Oxford University Press.

Mouritzen, P.-E./Svara, J. H. (2002): Leadership at the apex: Politicians and administrators in western local governments. Pittsburgh, PA: University of Pittsburgh Press.

Murray, J. Y./Kotabe, M./Zhou, J. N. (2005): Strategic alliance-based sourcing and market performance: evidence from foreign firms operating in China, in: Journal of International Business Studies, 36, 2, 187-208.

Murray, P./Donegan, K. (2003): Empirical linkages between firm competencies and organisational learning, in: The Learning Organization, 10, 1, 51-62.

Nakata, C./Sivakumar, K. (1996): National culture and new product development: An integrative review, in: The Journal of Marketing, 60, 1, 61-72.

Nisbett, R. E. (2003): The Geography of Thought : How Asians and Westerners Think Differently...and Why. New York: Free Publishing.

Nonaka, I./Takeuchi, H. (1995): The knowledge creating company: How Japanese companies create the dynamics of innovation New York: Oxford University Press.

Noorderhaven, N./Harzing, A.-W. (2009): Knowledge-sharing and social interaction within MNEs in: Journal of International Business Studies, 40, 5, 719-741.

Omerzel, D. G./Biloslavo, R./Trnavcevic, A. (2011): Knowledge management and organisational culture in higher education institutions, in: Journal for East European Management Studies 16, 2, 111-139.

Osterloh, M./Frey, B. S. (2000): Motivation, knowledge transfer, and organizational forms, in: Organization Science, 11, 5, 538-550.

Parsons, T./Shils, E. A. (1951): Toward a general theory of action. Cambridge, MA: Harvard University Press.

Podsakoff, P. M./MacKenzie, S. B./Lee, J.-Y./Podsakoff, N. P. (2003): Common method biases in behavioral research: A critical review of the literature and recommended remedies, in: Journal of Applied Psychology, 88, 5, 879-903.

Podsakoff, P. M./Organ, D. W. (1986): Self-Reports in Organizational Research: Problems and Prospects, in: Journal of Management, 12, 4, 531-544. 
Quigley, N. R./Tesluk, P. E./Locke, E. A./Bartol, K. M. (2007): A multilevel investigation of the motivational mechanisms underlying knowledge sharing and performance, in: Organization Science, 18, 1, 71-88.

Raudenbush, S. W./Bryk, A. S. (2002): Hierarchical linear models: Applications and data analysis methods (2nd ed.). Thousand Oaks, CA: Sage.

Rulke, D. L./Galaskiewicz, J. (2000): Distribution of knowledge, group network structure, and group performance, in: Management Science, 46, 5, 612-625.

Sagie, A./Mainiero, L. A./Koslowsky, M. (2000): Participation and empowerment in organizations: Modeling, effectiveness, and application. Thousand Oaks, CA: Sage.

Sagiv, L./Schwartz, S. H./Arieli, S. (2010): Personal values, national culture and organizations: Insights applying the Schwartz value framework. in: N. M. Ashkanashy, C. P. M. Wilderom \& M. F. Peterson (Eds.), The handbook of organizational culture and climate Thousand Oaks, CA: Sage.

Sanchez, R. (2001): Knowledge management and organizational competence. Oxford, UK: Oxford University Press.

Schein, E. H. (1992): Organizational culture and leadership. San Francisco, CA Jossey-Bass.

Schwab, A./Miner, A. S. (2008): Learning in hybrid-project systems: The effects of project performance on repeated collaboration, in: Academy of Management Journal, 51, 6, $1117-1149$.

Schwartz, S. H. (1999): Cultural differences: Some implications for work, in: Applied Psychology: An International Journal, 48, 23-47.

Schwartz, S. H. (2004): Mapping and interpreting cultural differences around the world. in: H. Vinken, J. Soeters \& P. Ester (Eds.), Comparing cultures, Dimensions of culture in a comparative perspective Leiden, The Netherlands: Brill, 43-73.

Schwartz, S. H. (2009): Culture matters: National value cultures, sources and consequences. in: C. Y. Chiu, Y. Y. Hong, S. Shavitt \& J. R. S. Wyer (Eds.), Understanding culture: Theory, research and application New York: Psychology Press., 127-150.

Senge, P. M. (1990): The fifth discipline: The art and practice of learning organization. New York: Currency Doubleday.

Shane, S. A./Venkatraman, S. (1996): Renegade and rational championing strategies, in: Organization Studies, 17, 5, 751-777.

Škerlavaj, M./Dimovski, V. (2009): Organizational learning and performance in two national cultures: A multi-group structural equation modeling approach in: W. R. King (Ed.), Knowledge Management and Organizational Learning New York: Springer US, 321366.

Škerlavaj, M./Štemberger, M. I./Škrinjar, R./Dimovski, V. (2007): Organizational learning culture: The missing link between business process change and organizational performance, in: International Journal of Production Economics, 106, 2, 346-367.

Slater, S. F./Narver, J. C. (1995): Market orientation and the learning organization, in: Journal of Marketing, 59, 3, 305-318.

Sorenson, O. (2003): Interdependence and adaptability: Organizational learning and the longterm effect of integration, in: Management Science, 49, 4, 446-463. 
Soulsby, A./Clark, E. (2011): Instability and Failure in International Joint Ventures in PostSocialist Societies: Power, Politics and Strategic Orientations, in: Competition and Change, 15, 4, 296-314.

Spector, P. E. (2006): Method Variance in Organizational Research: Truth or Urban Legend?, in: Organizational Research Methods, 9, 9, 221-232

Stata, R. (1989): Organizational learning: The key to management innovation, in: Sloan Management Review, 30, Spring, 63-74.

Triandis, H. C. (1995): Individualism and collectivism. Boulder, CO: Westview.

Triandis, H. C. (1998): Vertical and horizontal individualism and collectivism: Theory and research implications for international comparative management, in: Advances in International Comparative Management, 12, 7-35.

Trompenaars, F./Hampden-Turner, C. (1998): Riding the waves of Culture: Understanding cultural diversity in global business (2nd ed.). New York: McGraw-Hill.

Tsai, W. (2001): Knowledge transfer in intraorganizational networks: Effects of network position and absorptive capacity on business unit innovation and performance, in: Academy of Management Journal, 44, 5, 996-1004.

Tsang, E. W. K. (1997): Organizational learning and the learning organization: A dichotomy between descriptive and prescriptive research, in: Human Relations, 50, 1, 73-89.

Tsang, E. W. K. (1999): Internationalization as a learning process: Singapore MNCs in China, in: Academy of Management Executive, 13, 1, 91-101.

Tsang, E. W. K. (2002): Learning from overseas venturing experience: The case of Chinese family businesses, in: Journal of World Business, 17, 1, 21-40

Tucker, A. L./Nembhard, I. M./Edmondson, A. C. (2007): Implementing new practices: An empirical study of organizational learning in hospital intensive care units, in: Management Science, 53, 6, 894-907.

Vandenberg, R. J. (2006): Statistical and methodological myths and urban legends: Where, pray tell, did they get this idea?, in: Organizational Research Methods, 9, 2, 194-201.

Voelpel, S. C./Han, Z. (2005): Managing knowledge sharing in China: The case of Siemens ShareNet, in: Journal of Knowledge Management, 9, 3, 51-63.

Wagner, J. A. I. (1995): Studies of individualism-collectivism: effects on cooperation in groups, in: Academy of Management Journal, 38, 1, 152-172.

Walczak, S. (2008): Knowledge management and organizational learning: An international research perspective, in: The Learning Organization, 15, 6, 486-494.

Wang, X./Yang, B./McLean, G. N. (2007): Influence of demographic factors and ownership type upon organizational learning culture in Chinese enterprises, in: International Journal of Training \& Development, 11, 3, 154-165.

Wilkesmann, U./Fischer, H./Wilkesmann, M. (2009): Cultural characteristics of knowledge transfer, in: Journal of Knowledge Management, 13, 6, 464-477.

Williamson, D. (2002): Forward from a critique of Hofstede's model of national culture, in: Human Relations, 55, 11, 1373-1383.

Wittrock, M. C. (1974): Learning as a generative process, in: Educational Psychologist, 11, 2, $87-95$. 
Wittrock, M. C. (1992): Generative learning process of the brain, in: Educational Psychologist, 27, 4, 531-541.

Yammarino, F. J./Dansereau, F. (2010): Multilevel issues in organizational culture and climate research. in: N. M. Ashkanashy, C. P. M. Wilderom \& M. F. Peterson (Eds.), The handbook of organizational culture and climate Thousand Oaks, CA: Sage.

Zagoršek, H./Dimovski, V./Škerlavaj, M. (2009): Transactional and transformational leadership impacts on organizational learning, in: Journal of East European Management Studies, 14, 2, 144-165.

Zander, U./Kogut, B. (1995): Knowledge and the speed of the transfer and imitation of organizational capabilities: An empirical test, in: Organization Science, 6, 1, 76-92.

Zellmer-Bruhn, M./Gibson, C. (2006): Multinational organization context: Implications for team learning and performance, in: Academy of Management Journal, 49, 3, 501-518. 